ISSN 0104-4443

Licenciado sob uma Licença Creative Commons

\title{
Nietzsche e Freud: pensadores da modernidade
}

\author{
Nietzsche and Freud: philosophers of modernity
}

\section{Vincenzo Di Matteo}

Professor associado I da Universidade Federal de Pernambuco (UFPE), Recife, PE - Brasil, e-mail: dimatteo@nlink.com.br

\section{Resumo}

O texto aproxima dois pensadores da modernidade, Nietzsche e Freud, a partir de duas respectivas obras da maturidade: A genealogia da moral e O mal-estar na civilização. Após uma análise dos respectivos diagnósticos clínicos das patologias da época, além dos prognósticos e dos procedimentos terapêuticos por eles sugeridos, teceremos algumas considerações pessoais concernentes às contribuições dos dois pensadores para a compreensão de nosso mundo atual e aos desafios que permanecem em aberto para pensarmos uma teoria da vida e da cultura. Faremos isso com base neles, mas também contra e além deles, minimizando os riscos ideológicos que sempre pairam sobre esse empreendimento.

Palavras-chave: Nietzsche. Freud. Modernidade. Cultura. Patologia.

\section{Abstract}

This text approaches two thinkers of modernity starting from two of their maturity"s works, Moral genealogy and Civilization and its discontents. Following an analysis of the respec- 
tive clinical diagnosis of that period"s pathologies, the prognosis and therapeutic procedures suggested by them, the author considers these two thinkers" contributions to the comprehension of the present world and the challenges that remain open to think a theory of life and culture. It will be done based on these authors, but also against them and beyond them, minimizing the ideological risks that always scud over this enterprise.

Keywords: Nietzsche. Freud. Modernity. Culture. Pathology.

Em A Gaia Ciência, Nietzsche ([1882] 1976, p. 228) nos adverte: "Aquele que quer ser mediador entre dois pensadores recebe a marca da mediocridade; não tem visão para o único; as aproximações e os nivelamentos são características de olhos fracos". É provável que tenha razão, mais ainda em nosso caso. Aproximar dois pensadores, cujos respectivos pensamentos registram inflexões significativas, que não possuem e desconfiam de sistemas (FREUD, [1933] 1976; NIETZSCHE, [1881] 2004; [1888] 2006), que reivindicam originalidade em suas ideias (Nietzsche) ou pelo menos o mérito de terem desbravado caminhos singulares para se chegar a elas (Freud), é sem dúvida um empreendimento problemático. Mesmo assim, não faltaram razões para esse exercício de aproximação que fascinou, ao longo do século XX, romancistas, filósofos e psicanalistas.

Por que, então, retomar essa "famigerada conjunção" (NIETZSCHE, [1888] 2006), no nosso caso, de Nietzsche $e$ Freud? Não seria suficiente o veredicto freudiano quando, há mais de 100 anos, marcou suas diferenças ao julgar o projeto nietzschiano como uma tentativa injustificada de transformar o "ser" em "dever", um projeto alheio à ciência e, portanto, apenas moralista? ${ }^{1}$

O sentido de mais uma aproximação entre esses dois pensadores, em nosso caso, deve ser procurado, primeiramente, na conviç̧ão de que ambos são "pensadores" da modernidade e não apenas críticos

1 Em 1908, a recém-fundada Sociedade Psicanalítica de Viena, sucessora da "comunidade psicanalítica das quartas feiras" se confrontou por duas vezes com a obra de Nietzsche. Respectivamente, com A genealogia da moral em 01.04.1908 e Ecce Homo em 28.10.1908 (ASSOUN, 1991, p. 16-24).

Rev. Filos., Aurora, Curitiba, v. 23, n. 33, p. 269-286, jul./dez. 2011 
dela, isto é, não se limitaram a um mero diagnóstico clínico das patologias da modernidade, mas se arriscaram na emissão de um prognóstico e, em certos momentos, na sugestão de procedimentos terapêuticos. Em segundo lugar, no fato de que os consideramos, como a figura romana de Jano bifronte (a divindade dos limites), pensadores que demarcam os confins da modernidade e de nossa contemporaneidade.

Para operacionalizar essa confrontação, foram selecionados dois livros separados entre si por mais de 40 anos, mas que representam uma amostra significativa para nosso propósito por refletirem o pensamento maduro dos dois pensadores: A genealogia da moral (NIETZSCHE, [1887] 1998) e O mal-estar na civilização (FREUD, [1930] 1974).

Na primeira, de fato, deságuam temas e problemas importantes de obras anteriores, tais como a dupla pré-história do bem e do mal, o valor e a origem da moral ascética, da justiça, do castigo, ao mesmo tempo em que se anunciam os temas da decadência e do niilismo de grande importância para as obras seguintes. Na segunda, Freud retoma uma série de temas sobre moral e cultura abordados em textos anteriores e os articula, dessa vez, a partir da reformulação da teoria das pulsões em Além do princípio do prazer (FREUD, [1920] 1976) e do primeiro tópico em O ego e o id (FREUD, [1923] 1976). O que está em jogo nas duas obras são o valor da moral em Genealogia da moral (NIETZSCHE, [1887] 1998) e o valor da cultura em O mal-estar na civilização (FREUD, [1930] 1974), valores intercambiáveis na medida em que a má consciência na linguagem do primeiro e o sentimento inconsciente de culpa na do segundo constituem os dois principais sintomas que denunciam uma "doença" que se alastra da moral para outros domínios da cultura e desta para o psicológico e o fisiológico.

Nesse sentido, perguntamo-nos se e até que ponto seus diagnósticos e prognósticos relativos à moral e à cultura da modernidade dão conta também das "doenças" de nosso mundo globalizado ou se são fruto de dois médicos e psicólogos da cultura, certamente geniais, mas desatualizados para a inteligibilidade do nosso sofrimento contemporâneo.

Na leitura das obras mencionadas, daremos prioridade a uma chave de interpretação que podemos chamar de clínica. O objetivo é respeitar o procedimento genealógico nietzschiano, que articula indissociavelmente 
história, filologia, psicologia, fisiologia e medicina (NIETZSCHE, [1887] 1998), seja em atenção ao Freud da maturidade, que, em O mal-estar na civilização, pensa a cultura recorrendo aos modelos de sua metapsicologia (tópico, dinâmico, econômico), àquele filogenético-arqueológico, mas também ao modelo clínico de uma terapia das neuroses sociais segundo a analogia das neuroses individuais. Além disso, buscamos fazer jus a inúmeros significantes que pontuam as duas obras e remetem a uma realidade biopsicomédica.

\section{As patologias da modernidade na perspectiva de Nietzsche}

\section{Uma anamnese da doença do homem moderno}

A modernidade pensada por Nietzsche não é tanto um período histórico bem recortado no tempo, aquela cultural considerada orgulhosamente como uma ruptura positiva com o mundo dos antigos pelos modernos, mas como decadência por ele. Para ilustrar sua tese, o genealogista, filólogo e psicólogo procede, então, a uma espécie de anamnese desse homem moderno para mostrar-lhe que pretensos valores elevados, tais como o ideal ascético, o amor e a compaixão para com o outro, podem ser remetidos a suas origens mais prosaicas como a dívida material, a violência consigo mesmo, o medo do poder dos antepassados, o egoísmo. A orgulhosa autocompreensão do sujeito moderno como indivíduo soberano, dotado de consciência e vontade própria, não pode nos fazer esquecer que "nada foi comprado tão caro como o pouco de razão humana e sentimento de liberdade que agora constitui nosso orgulho" (NIETZSCHE, [1887] 1998, p. 104). ${ }^{2}$

Em linhas gerais, toda a história do pensamento ocidental, incluindo a da modernidade, é a história de um niilismo que se radicaliza, na medida em que a civilização é uma domesticação do homem: a vitória dos

\footnotetext{
Apenas para as citações da Genealogia da moral, dispensaremos a citação de autor-data e seguiremos o seguinte procedimento: $\mathrm{P}$, = Prólogo; I, II, III, = respectivamente Primeira, Segunda e Terceira Dissertação, seguido do número do tópico e do número da página da edição de 1998. Dessa maneira, julgamos que o leitor poderá com mais facilidade localizar o trecho citado também em outras edições. Os destaques em itálico são sempre dos respectivos autores (Nietzsche e Freud).
}

Rev. Filos., Aurora, Curitiba, v. 23, n. 33, p. 269-286, jul./dez. 2011 
escravos sobre os mais fortes mediante a invenção de "instrumentos da cultura" (NIETZSCHE, [1887] 1998), razões, justificações, ficções, convicções que, quando interiorizados pelo homem, destroem e pervertem a sua vontade de poder na qual reside a essência da vida.

Na reconstrução das origens e do desenvolvimento da consciência e da má consciência, descreve-nos o processo evolutivo pelo qual o animal humano se torna gradativamente um animal que pode fazer promessas, um ser de consciência, um animal doente, um animal de rebanho, ressentido e vítima de um ideal ascético culpabilizador e negador da vida. Naturalmente, a reconstrução-criação dessa anamnese sui generis determinará a validade e os limites do diagnóstico e prognóstico sobre o mal-estar da modernidade.

\section{Os sintomas culturais e seu diagnóstico: a neurose religiosa}

O significante "sintoma" é do próprio Nietzsche e ocorre várias vezes no texto. Não possui um significado técnico nem necessariamente pejorativo. A moral, por exemplo, deve ser entendida como consequência, sintoma, mas também como causa, medicamento (NIETZSCHE, [1887] 1998). Habitualmente, porém, reveste-se do significado mais geral entendido como um efeito que deixa entrever algo que se esconde nele, sob ele, por trás dele; foi precisamente isso que o levou a não poupar seus leitores de dar "uma olhada na imensidão de seus efeitos, também de seus efeitos funestos" (NIETZSCHE, [1887] 1998, p. 135).

Na modernidade, atendem pelo nome de depressões prolongadas, intoxicamento alcoólico, sífilis nos últimos tempos e, especialmente, neurose religiosa (NIETZSCHE, [1887] 1998) responsável por uma moral da compaixão que nega a vida e se alastra como “[...] o mais inquietante sintoma dessa nossa inquietante cultura europeia; como o seu caminho sinuoso em direção a um novo budismo? A um budismo europeu? A um niilismo?..." (NIETZSCHE, [1887] 1998, p. 11-12, grifo do autor).

A híbris do homem moderno pode até levá-lo a interpretar equivocadamente pretensas conquistas culturais - democracia, anarquismo, socialismo - como um progresso (NIETZSCHE, [1887] 1998). Não 
percebe, porém, que o que chama de um "avanço", um "progresso", deve ser considerado como sintoma regressivo, um retrocesso, sinais de uma vida que declina (NIETZSCHE, [1887] 1998).

A causa decisiva para o conjunto dessas doenças europeias da modernidade é a religião cristã com sua moral de ressentimento personificada na figura do sacerdote ascético, aquele que inventou o "grande estratagema" para aliviar a dor do homem ao responsabilizá-lo e culpabilizá-lo por seu sofrimento. Com isso, deu-lhe um sentido, pois o que o homem não suporta não é a dor, mas, sim, sua falta de sentido: “o homem preferirá ainda querer o nada a nada querer..." (NIETZSCHE, [1887] 1998, p. 149). Ao mesmo tempo, ministrou-lhe um remédio que não cura e que o torna ainda mais doente. Transformou, de fato, em pecado e punição (NIETZSCHE, [1887] 1998), p. 130) aquela primitiva "má consciência animal", adquirida quando o homem ficou "encerrado no âmbito da sociedade e da paz". Com essa interpretação, aquele inicial sentimento de culpa em seu estado bruto, da crueldade voltada para trás contra si mesmo, acabou se transformando em algo doentio: "Aqui há doença, sem qualquer dúvida, a mais terrível doença que jamais devastou o homem [...]" (NIETZSCHE, [1887] 1998, p. 81, grifo do autor) a ponto de a terra ter se transformado por muito tempo num hospício (NIETZSCHE, [1887] 1998)!

Foi esse ideal ascético, no entender de Nietzsche, o que mais destrutivamente agiu "sobre a saúde e o vigor de raça dos europeus; podemos denominá-lo, sem qualquer exagero, a autêntica fatalidade na história da alma do homem europeu" (NIETZSCHE, [1887] 1998, p. 132, grifo do autor) e, por ter corrompido a saúde da alma, corrompeu também o gosto nas artes e na literatura (NIETZSCHE, [1887] 1998).

\section{Prognóstico e terapêutica}

Se o diagnóstico é sombrio, o prognóstico nietzschiano está aberto para expectativas historicamente viáveis mesmo que não em curto prazo. Qual a estratégia proposta por Nietzsche? São apresentadas 
fundamentalmente duas: uma para "os acasos felizes" numa Europa doente e outra para os doentes.

Se a condição doentia do homem é a normalidade dentro da história, é preciso que os "acasos felizes", os "raros", os "sãos", os "mais fortes", os "bem logrados", os "vitoriosos", os "felizes", os "poderosos de corpo e alma" (NIETZSCHE, [1887] 1998, p. 111), protejam-se dos doentes com uma separação total, mantendo o pathos da distância. Não cabe a eles serem médicos, enfermeiros, consoladores, salvadores dos doentes. Estes que cuidem de si mesmos (NIETZSCHE, [1887] 1998).

Para os doentes do ideal ascético, o remédio é deixar de acreditar na mentira da existência de Deus, livrando-se do grande credor perante o qual têm uma dívida (culpa) impagável. Nietzsche (NIETZSCHE, [1887] 1998) até se permite deduzir que, gradativamente e até a vitória definitiva do ateísmo, a humanidade poderá se livrar da culpa e acessar a uma "segunda inocência". O problema é que mesmo "o ateísmo incondicional e reto" ainda está às voltas com sua vontade de verdade e não se opõe realmente ao ideal ascético (NIETZSCHE, [1887] 1998, p. 147).

$\mathrm{O}$ verdadeiro pharmacon (veneno e medicamento) que nos pode curar dessa doença da moral cristã se encontra nela mesma. Devemos a ela, de fato, com sua exigência de veracidade, sua bimilenar "educação para a verdade", sua necessidade de "asseio intelectual" e progressiva consciência científica na análise das coisas se hoje nos proibimos " $a$ mentira de crer em Deus" (NIETZSCHE, [1887] 1998, p.147, grifo do autor). Foi esse rigor intelectual que produziu "os bons europeus e herdeiros da mais longa e corajosa autossuperação da Europa" (NIETZSCHE, [1887] 1998, p. 148, grifo do autor).

Desaparecerá o cristianismo, não apenas como dogma, mas também como moral? Segundo Nietzsche, estaríamos no limiar desse acontecimento quando a moral cristã terá que tirar sua mais forte conclusão, aquela contra si mesma. Esse espetáculo em 100 atos será encenado nos próximos dois séculos da Europa e promete ser "o mais terrível, mais discutível e talvez mais auspicioso entre todos os espetáculos" (NIETZSCHE, [1887] 1998), p. 148).

Em longo prazo, portanto, o prognóstico para os doentes de ideal ascético é promissor, especialmente se consideramos a resposta que 
Nietzsche insinua às três perguntas que se coloca no final da segunda dissertação. Ele tem, sim, um projeto, o de derrubar o ideal da má consciência e de tudo que lhe está associado, isto é, os ideais hostis à vida e difamadores do mundo. Mas essa mensagem não se dirige aos homens "bons", "acomodados", "cansados", em suma, ao homem moderno herdeiro dessa estranha vocação artística de se moldar pela autotortura, mas a uma "outra espécie de espíritos" caracterizados por uma necessidade de conquista, perigo, dor, possuidores de "sublime maldade" própria de uma "grande saúde". Esta, porém, não é atingível no presente. "Algum dia", num "mais futuro" virá aquele que é descrito como o homem redentor, o homem do grande amor e do grande desprezo, o espírito criador, aquele que nos redimirá da vontade do nada e que devolverá "à terra sua finalidade e ao homem sua esperança, esse anticristão e antiniilista", cujo nome é Zaratustra, o ateu... (NIETZSCHE, [1887] 1998, p. 84-85, grifo do autor).

\section{As patologias culturais da modernidade na perspectiva de Freud}

\section{0 mal-estar como sintoma}

Não passa despercebida a um leitor minimamente atento a questão básica que perpassa o texto, isto é, a de um "mal-estar" na e da cultural em geral e da modernidade em particular (ROUANET, 1993). Um mal-estar aparentemente inexplicável e que pede uma inteligibilidade. Não é uma "crise" que se abate sobre um corpo orgânico ou social e que pode ser superada de alguma maneira. É mais um mal-estar permanente, indefinível e indefinido, que não permite um diagnóstico preciso nem um prognóstico consistente a não ser que produza sintomas finalmente dizíveis, finalmente falantes (PONTALIS, 1991).

Os principais sintomas falantes do mal-estar moderno detectados por Freud encontramos fundamentalmente na esfera da sexualidade e, especialmente, da agressividade (FREUD, [1930] 1974). O significante "sintoma" designa mais a primeira, e "sentimento inconsciente de culpa", a segunda (FREUD, [1930] 1974, p. 163). Há, porém, outros 
sintomas que falam em outras esferas setoriais da cultura, tais como a religiosa, a científica-técnica e a político-social, sendo que a própria cultura moderna como um todo pode ser considerada neurótica. Para cada um deles, Freud elabora um diagnóstico, um prognóstico e, em alguns casos, se permite até devaneios terapêuticos. Vamos apenas enumerá-los com um breve comentário para cada um.

\section{A religião como delírio de massa}

Das patologias culturais, destacamos, primeiramente, a religião em geral e o cristianismo em particular, que é a religião mais popular da Europa e que resistiu, com seus aspectos "patentemente infantis", ao projeto emancipatório da Ilustração. $\mathrm{O}$ cristianismo não é a fonte de todos os males da modernidade, como parece insinuar Nietzsche. Freud lamenta mais sua dimensão de delírio paranoico na medida em que se considera "a" única saída válida frente à dureza da vida e à tríplice fonte de sofrimento (FREUD, [1930] 1974, p. 95). Além disso, deprecia o valor da vida, mantém seus adeptos num estado de "infantilismo psicológico" e arrasta para um delírio de massa, mesmo que consiga poupar muitas pessoas de uma neurose individual (FREUD, [1930] 1974, p. 104).

\section{O sintoma do deus infeliz: a ilusão do progresso}

Freud não me parece perceber a modernidade como "decadente". Contrariando, porém, sua formação positivista, não identifica civilização e progresso, o que não passaria de um preconceito (FREUD, [1930] 1974, p. 117). Não desvaloriza, propriamente, o avanço técnico e sua importância "para a economia de nossa felicidade", mas constata que isso por si só "não aumentou a quantidade de satisfação dos modernos, nem os tornou mais felizes por não ser nem a única pré-condição da felicidade humana, nem o único objetivo do esforço cultural" (FREUD, [1930] 1974, p. 107). 
Pela sua definição de cultura ou civilização, que se encontra em O mal estar, ela tem duas funções: proteger os homens contra a natureza e ajustar os seus relacionamentos mútuos (FREUD, [1930] 1974, p. 109). Sem mencioná-lo explicitamente, Freud detecta certo fracasso do projeto iluminista (ROUANET, 1993). A Revolução Industrial e o progresso tecnológico, o progresso quantitativo (técnico) desacompanhado do progresso qualitativo (humanitário) (MARCUSE, 2001), não tornaram o homem mais feliz. Esse progresso não diminuiu nosso mal-estar e essa frustração cultural "fará exigências severas à nossa obra científica" e nos alerta que, se todas essas perdas não forem compensadas, "sérios distúrbios" podem surgir (FREUD, [1930] 1974, p. 118).

\section{0 sintoma da neurose sexual}

$\mathrm{Na}$ modernidade, teria havido um recrudescimento tanto das medidas repressoras contra a sexualidade polimorfa proscrita e até repudiada (FREUD, [1930] 1974, p. 125) quanto das restrições até para a sexualidade genital heterossexual, apenas tolerada e confinada ao casamento monogâmico. Essa super-repressão sexual gerou neurose, revolta e hipocrisia.

O prognóstico para essa patologia neurótica é incerto, mas não trágico. Conforme a bonita analogia entre um planeta que gira um torno de um astro sem renunciar a sua própria rotação sobre si mesmo, não seria utópico sonhar numa acomodação entre uma "ética de felicidade egoísta" e outra "altruísta" que atendessem tanto às necessidades dos indivíduos-sujeitos quanto às exigências pragmáticas da cultura (FREUD, [1930] 1974, p. 165). Essa luta, travada dentro da economia da libido, é comparável àquela referente à sua distribuição entre o ego e os objetos. Como é possível certa acomodação final no indivíduo, "podemos esperar, também, o fará no futuro da civilização, por mais que atualmente essa civilização possa oprimir a vida do indivíduo" (FREUD, [1930] 1974, p. 166). 
O paradoxo insolúvel se encontra na relação pulsão agressiva-cultura-sentimento de culpa.

\section{O sentimento inconsciente de culpa e agressividade}

A novidade de Freud com relação a Nietzsche na abordagem do sentimento de culpa consiste em conectá-lo com uma dupla origem: a ontogenética e a filogenética, a articulação da pequena história do desenvolvimento de cada um com a saga de Totem e tabu.

Desamparo infantil, medo da perda do amor, inicial "ansiedade social" (medo da autoridade), internalização da autoridade paterna com a superação do complexo de Édipo, estabelecimento do superego e o consequente medo desse olho de Deus secularizado, que substitui uma ocasional infelicidade externa decorrente do castigo por uma permanente infelicidade interna, constituem as etapas que levam ao verdadeiro nascimento do sentimento inconsciente de culpa quando a agressividade é punida mesmo que apenas desejada.

As analogias com o modelo filogenético do assassinato do pai primevo são evidentes, excetuando-se que, nesse "fato histórico plausível", a "culpa primária" (FREUD, [1930] 1974, p. 160) deveu-se a uma agressividade efetivamente consumada (FREUD, [1930] 1974). Nas duas histórias, fica evidenciado o importante papel desempenhado pelo amor na origem da consciência moral e a "fatal inevitabilidade do sentimento de culpa" (FREUD, [1930] 1974, p. 156), expressão da ambivalência afetiva e da luta entre Eros e Tanatos. Expressa-se inicialmente no complexo edipiano da família nuclear, seguida da família ampliada em comunidades e destas até a humanidade como um todo. A esse aumento do poder de Eros se encontra inextricavelmente ligado um aumento de sentimento de culpa.

A partir dessa interpretação da vida como portadora de duas pulsões, sendo que a pulsão muda da morte remete a uma "inata inclinação humana para a ruindade, a agressividade e a destrutividade, e também para a crueldade" (FREUD, [1930] 1974, p. 142), o prognóstico 
é sem esperança. O mal-estar não é algo contingente, mas estrutural, algo da alçada do ato de civilizar o homem.

Contra o gigante Tanatos só resta administrar o quantum excessivo de agressividade do superego cultural, tentar diminuir suas exigências que podem levar o mal-estar, expressão do sentimento inconsciente de culpa, a níveis insuportáveis (FREUD, [1930] 1974) e, finalmente, manter a pulsão de morte sempre imbricada com a de vida tanto para o sujeito quanto para a cultura.

\section{Superego cultural e neurose da cultura moderna}

Especialmente no último capítulo, Freud retoma as analogias entre o desenvolvimento libidinal do indivíduo e o processo civilizatório (FREUD, [1930] 1974), entre o superego individual e o cultural, mais especificamente entre neurose individual e sociedades neuróticas, entre uma terapêutica individual e a de determinadas comunidades culturais. Trata-se de uma analogia com suas semelhanças e importantes diferenças por ser o processo civilizatório um "processo especial" (FREUD, [1930] 1974, p. 118), e "amplia" a analogia, cedendo em parte "à tarefa tentadora" de mostrar que também a comunidade desenvolve um superego cultural de maneira semelhante à origem e ao desenvolvimento do superego individual.

Freud não rotula explicitamente a cultura moderna de neurótica, mas há vários indícios que justificam esse diagnóstico, especialmente a constatação de que há uma íntima relação entre superego individual e superego cultural. À neurose sexual decorrente das exigências excessivas do superego individual e cultural já detectada em Moral sexual civilizada e doença nervosa moderna (FREUD, [1908] 1976) acrescenta-lhe, no livro de 1930, aquela que é filha da pulsão agressiva. Administrá-la adequadamente se torna "o mais importante problema no desenvolvimento da civilização" (FREUD, [1908] 1976, p. 158), na medida em que um superego muito rígido produzirá revolta, neurose ou infelicidade (FREUD, [1908] 1976). A troca de "uma parcela de suas possibilidades de felicidade por uma parcela de segurança" 
(FREUD, [1908] 1976, p. 137), realizada pelo "homem civilizado" em geral, se tornou ainda mais problemática e dolorosa na modernidade porque o sofrimento do sujeito moderno provavelmente poderia ser evitado (FREUD, [1908] 1976).

Diagnosticado o mal-estar com tanta lucidez, era de se esperar que Freud nos apresentasse o remédio. Ele, porém, recusa-se a erguer-se como um profeta para consolar corações e mentes. Cada um terá que encontrar sua própria salvação para enfrentar a dureza da vida. Quanto ao futuro ético que nos espera, seu pensamento oscila entre uma tênue esperança de que o ser humano possa efetuar algumas alterações no curso da civilização e um "talvez" de resignação diante de um conflito intransponível (FREUD, [1908] 1976). Ao mesmo tempo, reconhece que, por tratar do ponto mais doloroso de toda a civilização, das relações dos seres humanos entre si, a ética pode ser considerada como uma tentativa terapêutica (FREUD, [1908] 1976). Não é uma ética religiosa ou "natural-narcísica". É uma ética que exige uma recompensa da virtude aqui na terra, uma ética até mesmo aberta para uma mudança real nas relações dos seres humanos com a propriedade, mas sem perder-se na "ilusão insustentável" dos socialistas que se equivocam a respeito da natureza humana ao acreditarem que a luta de classe desaparecerá com a abolição da propriedade privada (FREUD, [1908] 1976).

\section{Considerações finais}

É possível que a interpretação que apresentamos da leitura que Nietzsche e Freud fizeram da modernidade deixou de lado muitos outros aspectos que mereciam atenção. É, portanto, consciente ou inconscientemente, expressão do "violentar, ajustar, abreviar, omitir, preencher, imaginar, falsear e o que mais seja próprio da essência do interpretar" (NIETZSCHE, [1887] 1998, p. 139). Acrescentaria, a esses aspectos, a necessária contingência e historicidade que converte toda e qualquer interpretação numa tarefa infinita. Como Nietzsche ([1887] 1998) nos ensinou, só é definível o que não tem história. Não é o caso, portanto, de palavras como vida, cultura, culpa, doença, saúde, as quais 
foram ganhando uma rica polissemia ao longo dos séculos e que nos forçam a pensá-las e redescrevê-las indefinidamente.

No momento, resumiria minhas considerações a dez pontos, mais como homenagem do que como crítica aos dois "mestres da suspeita", que também poderíamos considerar como "mestres da modéstia" por apresentarem suas ideias como hipóteses, conjecturas, opiniões, perspectivas, pontos de vista, experimentações (FREUD, [1930] 1976; NIETZSCHE, [1987] 1998).

1) Mesmo reconhecendo a pertinência da advertência nietzschiana com a qual abrimos nosso texto, ratifico a conveniência de continuarmos essas aproximações. Elas nos podem ajudar a descobrir os vários, talvez inúmeros, "Freuds" e "Nietzsches" que encontraremos a cada releitura e privilegiar aquele Freud e aquele Nietzsche mais criativos, mais heurísticos, que nos ajudem a enxergar mais longe e alargar a compreensão que temos de nós mesmos e de nossa época.

2) Descontado o risco ideológico que sempre paira sobre teorias aparentemente meta-históricas, ambos vieram relembrar ao homem que a crueldade, a agressividade e a destrutividade constituem antigos e provavelmente indeléveis substratos da cultura (FREUD, [1930] 1974; NIETZSCHE, [1908] 1995).

3) Penso que a leitura que Nietzsche e Freud fazem da modernidade assenta, fundamentalmente, numa crítica à concepção de sujeito, psiquismo, racionalidade, consciência ou como queira se denominar a compreensão exaltada que o homem moderno fez de si mesmo a partir do chamado logocentrismo ocidental europeu. A alternativa proposta é a primazia dada a uma determinada concepção de vida, de instintos e de pulsões que permitem explicar e compreender o mundo orgânico, o desenvolvimento do indivíduo empírico e até mesmo o desenvolvimento da cultura.

4) Até que ponto, porém, a concepção de vida (palavra pivô, o pressuposto dos pressupostos nietzschianos para julgar a valorização das tábuas de valores de uma determinada moral e o critério último para diferenciar saúde e doença) deve ser entendida, "essencialmente", 
em suas funções básicas, como o que "atua ofendendo, violentando, explorando, destruindo, não podendo sequer ser concebida sem esse caráter"? (NIETZSCHE, [1887] 1998, p. 65). Trata-se de um fato ou de "uma" interpretação que conserva as marcas de uma época?

5) Uma problematização parecida pode ser dirigida às duas pulsões detectadas por Freud a partir de "especulações sobre o começo da vida e de paralelos biológicos" (NIETZSCHE, [1887] 1998, p. 141). Em ambos os casos, o que está em jogo é o problema de uma teoria da vida e dos riscos ideológicos e metafísicos que a perpassam.

6) É verdade que a ancoragem da cultura ao mundo das pulsões e da vida vem nos lembrar a precariedade dela para solucionar os problemas humanos, pois não possui uma autonomia essencial sobre uma natureza, que parece indiferente à nossa felicidade ou infelicidade (FREUD [1930] 1974). No entanto, não deveria nos levar a dissolver o humano no biológico e no natural como se neles se encontrasse o álibi ou a redenção de nossos comportamentos culposos ao nos justificar de nossos "pecados" libidinosos ou agressivos. É verdade, afirma Laplanche (1997), que o homem é, às vezes, não apenas um vivente, mas uma besta agressiva e depravada, mas remeter nosso fundo último à animalidade é uma concepção puramente fabricada, ideológica. ${ }^{3}$

7) Com relação às patologias culturais, penso que a grade de leitura da modernidade tanto de Nietzsche quanto de Freud não pode ser transposta automaticamente para compreensão de nossas patologias contemporâneas. No caso específico do fundador da psicanálise, o que é questionável não é apenas o "mito científico" do Pai da horda, já criticado pelos antropólogos. A própria teoria do Édipo ontogenético, com muita probabilidade, é fruto do momento histórico específico em que foi formulada, ao pensar o indivíduo e seu mal-estar dentro de uma sociedade monogâmica

3 Conferência pronunciada na Universidad Nacional de Buenos Aires e na Universidad de La Republica, em Montevideo, em outubro de 1997 e, no contexto da III Jornada Norte-Nordeste do Círculo Brasileiro de Psicanálise, II Jornada da Sociedade Psicanalítica da Paraíba, de 7 a 9 de novembro de 1997 em João Pessoa. A conferência, traduzida e gentilmente distribuída aos participantes, tem como título "Psicanálise e biologia: realidades e ideologias". 
e de capitalismo industrial (MARCUSE, 1970). Hoje, parece que o superego cultural de que nos fala Freud foi substituído por um novo tipo aparentemente mais fraco, mais liberal, menos exigente e culpabilizador, mais tolerante e permissivo, mais afinado com nossa sociedade de consumo. Mesmo assim, também esse deus pós-moderno, como o deus de prótese descrito por Freud (FREUD, [1930] 1974, p. 111), é também um deus infeliz e sua infelicidade atende pelo nome de depressões, toxicomanias, síndrome do pânico, distúrbios alimentares (bulimia, anorexia), ansiedade, angústia, desamparo, paranoia e mania. Segundo os próprios psicanalistas (BIRMAN, 1999; COSTA, 2000), essas novas formas de sofrimento e de modalidades de inscrição da subjetividade no mundo da atualidade precisariam de novos instrumentos interpretativos.

8) Esses novos diagnósticos e prognósticos não serão fornecidos por uma razão solitária, mesmo que privilegiada como as de Nietzsche e Freud. Será um empreendimento necessariamente conjunto, fruto de uma multiplicidade de contribuições como expressão concreta de uma "racionalidade comunicativa" que dialoga ad intra com o mundo das ciências da vida e ad extra com os outros e seus pluralismos culturais.

9) Construir um mundo pessoal e comunitário, que seja paradoxalmente mesmo e outro, singular e universal, mais livre e seguro, menos sofrido se não puder ser feliz, será um esforço também infindável, mas nosso, humano, mesmo que sobre-humano ou simplesmente "pós-humano". Não é animado por uma esperança de natureza religiosa, nem por uma certeza teleológica de caráter filosófico. Trata-se apenas de uma aposta na razoabilidade dos humanos, sem as garantias de um final feliz.

10) No âmbito da micro-história individual, apesar de nosso assujeitamento às forças das pulsões e às exigências normativas e restritivas da cultura, sempre resta para cada um uma difícil e inalienável tarefa ética, não apenas moral, isto é, de assumir a própria vida sem as próteses da consolação e da ilusão e tentar, na medida do possível, fazer dela uma obra de arte, uma 
invenção permanente de si mesmo a partir de uma convivência pelo menos tolerante - se não puder ser amistosa - com todos aqueles com os quais teremos que necessariamente compartilhar uma história, um mundo, nossos sonhos e nossos pesadelos.

\section{Referências}

ASSOUN, P-L. Freud e Nietzsche: semelhanças e dessemelhanças. 2. ed. São Paulo: Brasiliense, 1991.

BIRMAN, J. O mal-estar na atualidade: a psicanálise e novas formas de subjetivação [da pós-modernidade]. Rio de Janeiro: Civilização Brasileira, 1999.

COSTA, J. F. Playdoier pelos irmãos. In: KEHL, M. R. (Org.). Função fraterna. Rio de Janeiro: Relume Dumará, 2000. p. 7-30.

FREUD, S. Moral sexual "civilizada" e doença nervosa moderna. Edição Standard Brasileira das Obras Psicológicas Completas. Rio de Janeiro: Imago, 1976. Publicado originalmente em 1908.

FREUD, S. Além do princípio do prazer. Edição Standard Brasileira das Obras Psicológicas Completas. Rio de Janeiro: Imago, 1976. Publicado originalmente em 1920.

FREUD, S. O ego e o id. Edição Standard Brasileira das Obras Psicológicas Completas. Rio de Janeiro: Imago, 1976. Publicado originalmente em 1923.

FREUD, S. O mal-estar na civilização. Edição Standard Brasileira das Obras Psicológicas Completas. Rio de Janeiro: Imago, 1974. Publicado originalmente em 1930.

FREUD, S. Novas conferências introdutórias sobre a psicanálise: conferência XXXV: a questão de uma Weltanschauung. Edição Standard Brasileira das Obras Psicológicas Completas. Rio de Janeiro: Imago, 1976. Publicado originalmente em 1933. 
LAPLANCHE, L. Psicanálise e biologia: realidades e ideologias. In: JORNADA NORTE-NORDESTE DO CÍRCULO BRASILEIRO DE PSICANÁLISE, 3.; JORNADA DA SOCIEDADE PSICANALÍTICA DA PARAÍBA, 2., 1997. João Pessoa. Anais...João Pessoa: [s.n.], 1997.

MARCUSE, H. O envelhecimento da psicanálise. In: REICH, W. et al. Psicanálise e sociedade. Lisboa: Presença, 1970.

MARCUSE, H. A noção de progresso à luz da psicanálise. In: MARCUSE, H. Cultura e psicanálise. São Paulo: Paz e Terra, 2001. p. 112-138.

NIETZSCHE, F. Aurora. São Paulo: Companhia das Letras, 2004. Publicado originalmente em 1881.

NIETZSCHE, F. A gaia ciência. São Paulo: Hemus, 1976. Publicado originalmente em 1882.

NIETZSCHE, F. Genealogia da moral: uma polêmica. São Paulo: Companhia das Letras, 1998. Publicado originalmente em 1887.

NIETZSCHE, F. O crepúsculo dos ídolos, ou como filosofar com o martelo. São Paulo: Companhia das Letras, 2006. Publicado originalmente em 1888.

NIETZSCHE, F. Ecce Homo. São Paulo: Companhia das Letras, 1995. Publicado originalmente em 1908.

PONTALIS, J.-B. Atualidade do mal-estar. In: PONTALIS, J.-B. Perder de vista. Rio de Janeiro: J. Zahar, 1991.

ROUANET, S. P. Mal-estar na modernidade. São Paulo: Companhia das Letras, 1993.

Recebido: 23/06/2011

Received: 06/23/2011

Aprovado: 21/07/2011

Approved: 07/21/2011 